\title{
EVALUATION OF STUDENT'S OPINION ABOUT OSCE FOR GRADUATE NURSING STUDENT -SHENDI UNIVERSITY SUDAN2012
}

Dr. Higazi Mohammed Ahmed Abdallah Awad *1

${ }^{* 1}$ BSc, MSc, Ph D, MSN, Assistant Professor of Medical Surgical Nursing Faculty of Nursing Shendi University

\section{Abstract:}

This study was done in Sudan, NaherElneel state, shendi town, at shendi university faculty of nursing during September 2011. Seventy three second-year nurses students were asked to complete a brief anonymous questionnaire regarding their opinion as a new trend clinical exam strategy. The questionnaire was administered to all students post OSCE exam and required approximately ten minutes to complete it.68\% of student agree that OSCE had covered wide area of knowledge and practice rather than ordinary exam. Few students were considered that $\mathrm{OSCE}$ is stressful and relatively intimidating. Majority of the student recommended that increasing time per station.

The study aim to evaluate the student opinion about OSCE for undergraduate nursing student, so as to test the validity and reliability of the exam among them.

The study concluded that, most of the student agreed that OSCE is better method of clinical evaluation because the matter of bias is minimum and it's less stressful as compare with the ordinary exam. Also they were agreed that OSCE allow chance of compensation for poor performance.

The study recommended that, OSCE should be integrated within the curriculum in conjunction with other relevant evaluation methods.

Keywords:

Nursing student, OSCE, Clinical Evaluation, evaluation methods.

Cite This Article: Dr. Higazi Mohammed Ahmed Abdallah Awad, "EVALUATION OF STUDENT'S OPINION ABOUT OSCE FOR GRADUATE NURSING STUDENT -SHENDI UNIVERSITY SUDAN2012" International Journal of Research - Granthaalayah, Vol. 3, No. 7(2015): 91-102. DOI: https://doi.org/10.29121/granthaalayah.v3.i7.2015.2989.

\section{INTRODUCTION}

Assessment of clinical competence is an essential requirement of health professional education. Since its development in the 1970s, the Objective Structured Clinical Examination (OSCE) has gained acceptance as a benchmark for clinical skills assessment (Bartfay, et al 2004).

The OSCE is defined as "an approach to the assessment of clinical competence in which the components of competence are assessed in a well-planned or structured way with attention being paid to objectivity" (Harden 1988, p. 19 , ( or as an assessment of well-defined clinical skills (Ward \& Willis 2006). 


\section{INTERNATIONAL JOURNAL OF RESEARCH -GRANTHAALAYAH

An OSCE requires each student to demonstrate specific skills and behaviors in a simulated work environment with standardized patients. It typically consists of a circuit or series of short assessment tasks (stations), each of which is assessed by an examiner using a predetermined, objective marking scheme (Bartfay et al 2004; Major 2005; Ward\&Barratt 2005).

The OSCE has become a well-established method of assessment in medical education (Ward \& Barratt 2005) and is increasingly being used as a method of assessment in nursing and allied health curricula (Bartfay et al 2004; Wessel et al 2003 .(A framework for the development of clinical competence has been described) Miller 1990) which outlines four levels at which a learner can be assessed: knows, know show, shows how and does (see Figure 1). The OSCE conforms to the third shows how level of Miller's pyramid (see Figure 1) which focuses on assessment of performance of specific skills in a controlled setting (Hamdy 2006; Issenberg et al 2005; Schuwirth\&van der Vleuten 2003; Selby et al1995). This makes it particularly relevant for the early stages of undergraduate curricula, where assessment comprises compartmentalized exercises (Friedman Ben-David 2000).

Furthermore, as a method of clinical skills assessment, the OSCE possesses a number of intrinsic advantages. Firstly, it can include both summative and formative components, in which a judgment or evaluation of an individual's performance is made summative followed by the provision of feedback, from which the student can learn) formative (Taras 2005). Secondly, because each student is required to demonstrate specific behaviors in a simulated work environment, strict control over the clinical context is possible, while at the same time, reflecting real-life professional tasks. This control eliminates the 'luck of the draw' problem that arises when students are assessed within the 'real-world' clinical environment with actual patients (Bartfay et al 2004) as well as the risk of harm occurring to a patient. The underlying premise is that such standardized procedures ensure objectivity and maximize reliability in assessment (Bartfay et al 2004; Major 2005).

The purpose of this paper is to review and evaluate the range of approaches and applications of OSCEs in health professional education, and to make recommendations as to how OSCEs may best be used in the assessment of nurse undergraduates. In doing so, we discuss the differences between examinations undertaken in a simulated environment versus the 'real world' in the evaluation of student performance as well as the performance and cognitive level at which nurse undergraduates function. These considerations assist in delineating the competency components or skill sets that best lend themselves to evaluation by OSCEs .

\section{APPLICATION OF THE OSCE TO NURSE EDUCATION}

Since its inception in 1979, the OSCE has become widely recognized as an effective assessment instrument, both in terms of the types of skills tested and the number of tasks that can be incorporated into the assessment. The original OSCE Harden et al 1975 comprised a series of 16 to 20 stations, with each station taking approximately five minutes to complete, and was specifically focused on clinical skills assessment of medicine students. Since then, however, the 


\section{INTERNATIONAL JOURNAL OF RESEARCH -GRANTHAALAYAH

OSCE has been adapted for use in other health professional curricula, particularly nursing. Many of these adaptations feature longer, fewer stations or case scenarios that concentrate on a total patient consultation Bujack et al 1991a. Typically, total patient format comprises one integrated station of approximately 30 minutes or longer. This latter approach has been referred to as an Objective Structured Clinical Assessment (OSCA) because of its more complete and holistic assessment rather than a specific, focused examination or evaluation of a sub-component of a patient assessment (Ward \& Willis 2006; Rush forth 2007. (Applications of OSCEs with its many stations with the focus on specific tasks or skills vary from the single integrated assessment station of an OSCA which provides an holistic patient assessment (Major, 2005). The OSCA single station integrates many areas such as communication skills, observation and recording of vital signs, assistance with personal hygiene, movement from bed to chair, observations, and reporting of wound status. Khattab and Rawlings (2001) report using a two-component OSCA for student nurses: one for tasks (skills assessment) and one for questions (knowledge assessment .(The emphasis in the first component was on techniques and communication skills; and inthe second on the clinical findings and their student's interpretation of these findings . Students were required to perform a whole examination including a general examination of cardiovascular, respiratory, nervous, and musculoskeletal systems and the abdomen and glands. Students were then questioned on three levels of cognitive activity :knowledge of anatomy and physiology, clinical reasoning, and the relationship of the physical examination to clinical significance .However, the multi-station OSCEs have also been used for undergraduate nurse students to assess not only advanced clinical practice skills but also student's interpretation of these findings. Ward and Barratt (2005), developed a 10-station.

OSCE consisting of three physical examination stations, three history taking stations, three communication stations (incorporating interpretation and giving a laboratory result, patient management, patient education / health promotion, and exploration of a problem relating to mental health), and one question-and-answer station. Others have used even larger OSCEs - up to 20 stations - with a wide array of skills being incorporated for evaluation (Chesser et al 2004; Wilkinson et al 2000; Humphrey Murto\&MacFadyen.(2002In short, there is a broad variety in the application of the OSCE, ranging from assessment of the purely technical - evaluating brief tasks or students' acquisition of skills, to assessment of professional competence - evaluating intellectual components such as clinical judgment and/or integration of a range of skills and knowledge refer).

\section{VALIDITY AND RELIABILITY}

Intuitively, it makes sense to use OSCEs (i.e. many stations) because they have high face validity (Newstead 1992), that is, both students and examiners see them as measuring skills relevant to clinical practice. Moreover, a large part of the success of the OSCE in its original form was because it was found to be more reliable and valid than other more traditional forms of clinical assessment, such as long cases and viva voce examinations (Bartfay et al 2004; Brosnan et al 2006; Harden \& Gleeson 1979). 


\section{INTERNATIONAL JOURNAL OF RESEARCH -GRANTHAALAYAH

However, despite consistent findings of high face validity (Ward \& Barratt 2005; Brosnan et al 2006; Bujack et al 1991b), the large number of adaptations has resulted in inconsistencies in the reliability and validity of the OSCE, which have been well documented (Rushforth 2007). To overcome these and ensure acceptable reliability and content validity, a recurring recommendation in the literature is to include a larger number of short stations (approximately five minutes) (Schuwirth\& van der Vleuten 2003; Selby et al 1995; Bartfay et al 2004). In particular, the need for more rigorous evaluation of OSCEs in nurse education programs has been highlighted (Khattab\& Rawlings 2001; Brosnan et al 2006), as these assessments are directed towards assurances that passing students can practice safely in the clinical setting with patients.

\section{APPROPRIATE USE OF OSCES}

Given the wide variety of assessment tasks to which the OSCE has been applied, there is a need to explore how and where they may best be used within the nurse undergraduate curriculum (Salas \& Burke 2002). In addressing this issue, it is particularly important to consider the effect on reliability and validity of using the OSCE for different types of assessment tasks. Four essential areas of revising competence will now be discussed in relation to OSCEs. i) Measuring context-reliant competence: Nursing is a dynamic process that constantly changes in response to a variety of social contextual influences making it difficult to replicate within an examination context (Benner 1984; Hodges 2003a; McMullen et al 2003; Piercey 1995). McMullen et al (2003) argue that if the objective of the assessment is to obtain a holistic perspective of competence, then complex combinations of knowledge, skills, attitudes and values need to be brought together in context-specific situations that incorporate interacting contextual factors and ethics. Case in point is the myriad of organizational demands, for example staffing and vailability of appropriate resources, placed on a nurse that may mediate the nature of the nurse's critical thinking ability and behaviour, at a specific point in time. Valuating critical thinking skills such as problem-solving, clinical reasoning, decision-making, by simulated assessment cannot capture the complex and changing nature of generational demands (Benner 1984). Insofar as the OSCE is unable to take account of interacting contextual factors that are common in the clinical environment, this presents a major limitation with regard to its predictive validity when used for this purpose. Although an important advantage of the OSCE is its ability to provide a standardized clinical assessment, it is this very advantage which prevents it accommodating the myriad cultural, economic and sociopolitical contexts that exist within the larger clinical nursing context (McGrath et al 2006). In other words, the level of competence in critical thinking as assessed by an OSCE is unlikely to fully reflect the student's ability to competently apply critical thinking in the real-life clinical setting. ii) Measuring Competence versus Measuring Performance: Circular logic is an important factor that affects the predictive validity of all forms of observed assessment including the OSCE, and highlights the difference between assessment of competence and the assessment of performance. OSCEs assess the presence of behaviours that the OSCE itself has the proclivity to affect (Hodges 2003a). To illustrate, sociologist Goffman (1959, cited in Hodges 2003b), notes that when emphasis is placed on performance of a social interaction such as ensuring a patient's psychological comfort through the use of effective 


\section{INTERNATIONAL JOURNAL OF RESEARCH -GRANTHAALAYAH \\ A knowledge Repository}

Science

communication and interpersonal skills and empathic treatment, individuals become adept at altering their performance to portray an interaction they believe would demonstrate their competence. That is, the examination context itself may encourage the individual to behave in a socially desirable manner which may not truly reflect the way the individual would perform in a real world situation. Thus, one may query the extent to which OSCEs adequately assess some psychosocial skills sets / competency components and consequently query the OSCE's predictive validity for these types of competencies. iii) Measuring Professional Behaviour: Nursing practice is complex, consisting of a mix of different competency components. Some, such as technical skills, are essential for safe practice, are readily quantified using standardized instruments, while others require a more qualitative approach (McGrath et al 2006). For example, there are difficulties inherent in measuring the construct of caring - a core component of nursing practice (McGrath et al 2006). Specifically, an OSCE may not be able to adequately assess the range of behaviours within the concept of caring. As Bartfay et al $(2004$, p.19) state, "the completeness of an examination depends on the number of behaviours sampled"; and as McGrath et al (2006) illustrate further, the aspects that are assessable in an OSCE may not be sufficient to confirm (or refute) that the nurse is in fact, a caring nurse. Thus, the assessment of complex and essentially subjective constructs, such as caring, empathy and other interpersonal skills are vulnerable to findings of low validity and poor inter-rater reliability within an OSCE. Again, contextual information is needed to judge the appropriateness of a nurse's behaviour; therefore the extent to which psychosocial constructs, such as caring, are appropriate for evaluation via the OSCE approach is questionable. iv) Measuring Integration of Skills: Another concern that needs to be addressed when developing an OSCE is its potential to reduce nursing practice to a mere set of tasks to be performed, raising concern that the patient will not be viewed as a whole (Brosnan et al 2006; Major 2005). To overcome this matter, Bujack et al (1991a) recommended structuring the assessment such that all stations relate to one scenario (the long case), reflecting the philosophy of holistic patient care. They reported that this could enable students to "integrate a range of knowledge and skills and to demonstrate the use of these in planning, implementing and evaluating care given in response to a single patient encounter" (Bujack\& little; cited by Major 2005, p.443). The concept of assessing integration of skills in nurse undergraduates contravenes Benner's (1984) Novice to Expert taxonomy which describes the development of competence. Benner defines the performance of junior undergraduate nurses as being at the novice level, where the focus is on remembering rules with little or no attention being paid to contextual factors. Specifically, novices concentrate on learning discrete, context-free skills such as measuring patients' weight, recording fluid intake and output, temperature, blood pressure, pulse and other such "objectifiable, measurable parameters of a patient's condition" (Benner 1984, p.20). Benner's conclusion that nursing students operate at the novice level has been echoed by others (Ellerton\&Gregor 2003; Fisher \&Parolin 2000; Pigott 2001; Watkins 2000) and includes recognition of an approach to nursing practice that is largely procedural (Ellerton\&Gregor 2003). Major (2005) acknowledged the benefits of assessing discrete skills for novices, and introduced workstation activities such as urine testing, injection technique and resuscitation technique, as well as the skills required for safe practice prior to students' first clinical placement, including hand washing, basic life support and safe manual handling (Major 2005). For second year undergraduates, Major (2005) recognizes taxonomies of learning through the use of OSCEs 


\section{INTERNATIONAL JOURNAL OF RESEARCH -GRANTHAALAYAH

where more complex skills are divided into a series of related steps. Similarly, Friedman BenDavid (2000), who has contributed significantly to developing protocols for OSCE construction, recommends an approach similar to Major (2005) where simulations in assessment should progress from discrete to integrated abilities, as the student progresses through their degree. Not only is this recommendation in line with Benner's Novice to Expert taxonomy (Benner et al 1996), it also supports the notion that an important requirement in using OSCEs is to ensure that the level of the assessment task is consistent with the expected level of performance and limited clinical experience, rather than attempting to take an integrated holistic approach which incorporates more complex cognitive processes such as critical thinking. Matching Assessment to Expected Level of Competence Three factors indicate that at the undergraduate level, OSCEs are best used for the assessment of discrete sycho motor skills -Firstly that undergraduate nurses operate towards the novice end of the novice-expert continuum. Secondly, that nurses must be sufficiently competent for safe practice prior to clinical placement, and finally acknowledgement of the difficulties of replicating a real-world clinical environment in an examination context. (Borbasi\& Koop 1993; Bartfay et al 2004). Students may possess procedural knowledge ("knowing how") without declarative ("knowing that") or schematic knowledge ("knowing why") (Burnard 1987; Shavelson\& Huang 2003). For instance, a student might know how to administer an intravenous antibiotic without knowing why it was given or knowing that certain complications may develop due to its administration (Burnard 1987). To ensure that assessment encompasses conceptual understanding as well as dexterity and precision of movement, assessing psychomotor skills in combination with the knowledge that underlies their safe application is recommended with the understanding that synthesis of the two types of knowledge does occur - more often towards the end of a unit of study (Khattab\& Rawlings 2001).

\section{METHODOLOGY \& MATERIAL}

\section{STUDY DESIGN}

This study was descriptive cross sectional research done at faculty of nursing Shendi January 20012 to May 20012 to Evaluate the student`s opinion about OSCE.

\section{STUDY AREA}

The research was done in Sudan in Shendi town, in the Revier Nile state, which located $174 \mathrm{Km}$ north of the capital Khartoum.

Shendi University was established in the year 1990 and it include different collages, medicine, arts, science, low, laboratory, and nursing faculties.

\section{STUDY POPULATION}

Its include semester eight student.

\section{SAMPLING}

Total coverage sample. 


\section{INTERNATIONAL JOURNAL OF RESEARCH -GRANTHAALAYAH

\section{DATA COLLECTION TOOLS}

Standard closed ended questionnaire was developed by the researches based on available literature to evaluate the student`s opinion about OSCE.

\section{DATA COLLECTION TECHNIQUE}

The data was collected within two weeks every participant filled the questionnaire by him / herself. Each questionnaire take from (4 to 8 ) minute to be filled, there was no missing questionnaire.

\section{ETHICAL CONSIDERATIONS}

Permission has been taken from dean faculty and the institutional research board of the faculty. The purpose of the study was explained to every student.

\section{DATA ANALYSIS TECHNIQUE}

The data was analyzed manually by simple statistical method and presented in forms of table.

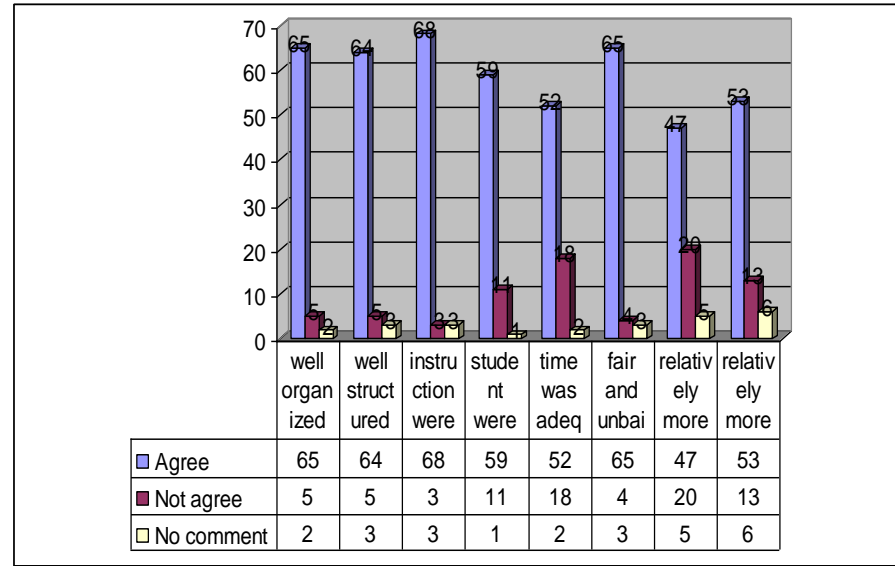

Figure 1: The distribution of the student opinion about OSCE organization

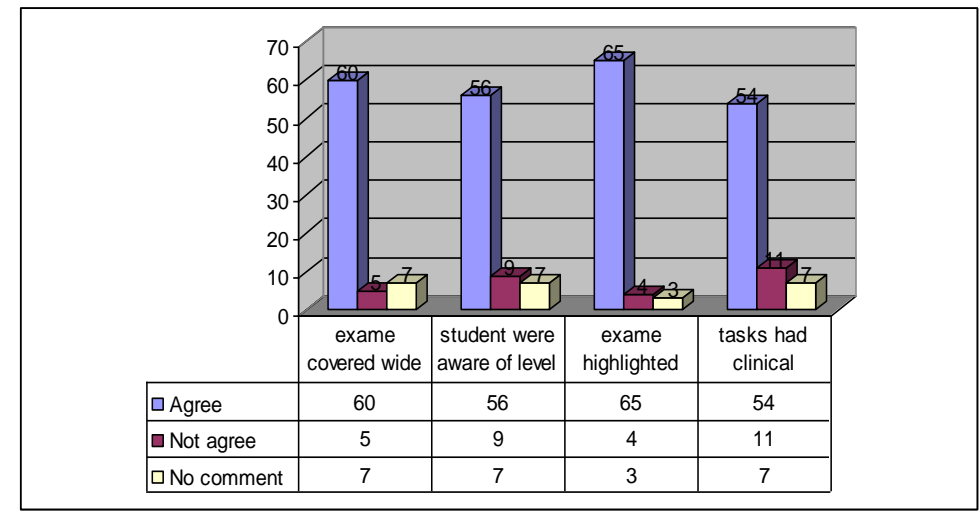

Figure 2: The distribution of the student opinion and knowledge about OSCE exam 


\section{INTERNATIONAL JOURNAL OF RESEARCH -GRANTHAALAYAH}

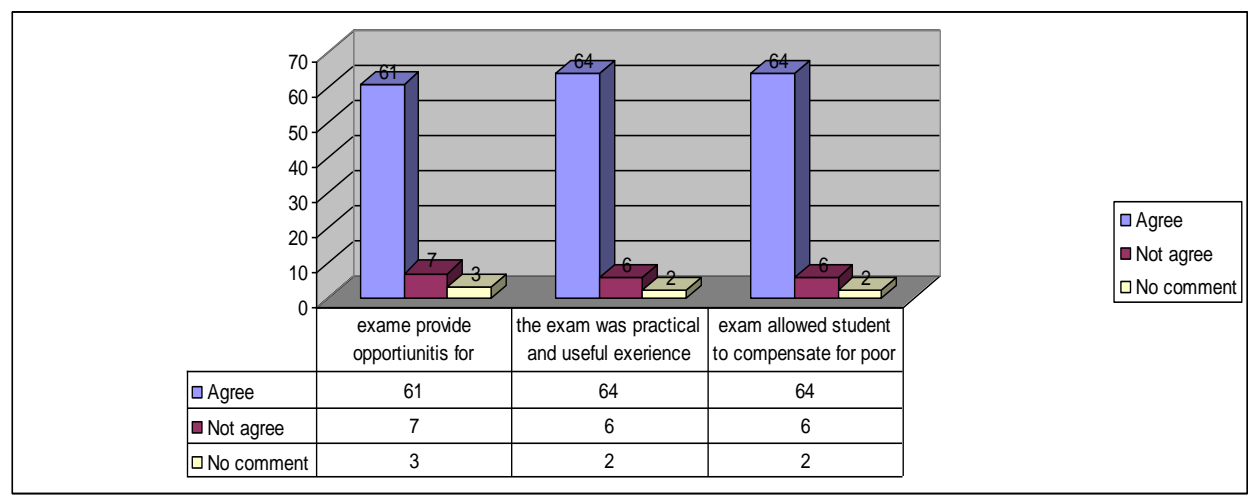

Figure 3: the distribution of the student opinion and about OSCE practice

Table 1: Student comment regarding disadvantage of OSCE exam

\begin{tabular}{|l|l|l|}
\hline Disadvantage & Frequency & Percentage \\
\hline $\begin{array}{l}\text { More } \\
\text { intimidating }\end{array}$ & 15 & $20.8 \%$ \\
\hline $\begin{array}{l}\text { Time not } \\
\text { enough }\end{array}$ & 5 & $6.9 \%$ \\
\hline $\begin{array}{l}\text { Stress full } \\
\text { exam }\end{array}$ & 10 & $13.9 \%$ \\
\hline Total & 30 & $41.6 \%$ \\
\hline
\end{tabular}

Table 2: Student comment regarding advantage of OSCE exam

\begin{tabular}{|l|l|l|}
\hline Advantage & Frequency & Percentage \\
\hline $\begin{array}{l}\text { Fair and } \\
\text { unbiased }\end{array}$ & 42 & $58.3 \%$ \\
\hline $\begin{array}{l}\text { Practical } \\
\text { and useful }\end{array}$ & 62 & $86.1 \%$ \\
\hline $\begin{array}{l}\text { Organized } \\
\text { and clear }\end{array}$ & 64 & $88.8 \%$ \\
\hline $\begin{array}{l}\text { Covered } \\
\text { wide } \\
\text { knowledge } \\
\text { area }\end{array}$ & 55 & $76.3 \%$ \\
\hline
\end{tabular}




\section{INTERNATIONAL JOURNAL OF RESEARCH -GRANTHAALAYAH \\ A knowledge Repository}

Table 3: Student recommendation to improve OSCE exam

\begin{tabular}{|l|l|l|}
\hline Recommendations & Frequency & Percentage \\
\hline $\begin{array}{l}\text { To reduce task } \\
\text { contents }\end{array}$ & 35 & $48.6 \%$ \\
\hline $\begin{array}{l}\text { To increase time } \\
\text { per station }\end{array}$ & 65 & $90.2 \%$ \\
\hline $\begin{array}{l}\text { To reduce station } \\
\text { number }\end{array}$ & 23 & $31.9 \%$ \\
\hline $\begin{array}{l}\text { To involved } \\
\text { expert nurse for } \\
\text { exam }\end{array}$ & 12 & $16.7 \%$ \\
\hline
\end{tabular}

\section{CONCLUSIONS}

The study concluded that, most of the student agreed that OSCE is better method of clinical evaluation because the matter of bias is minimum and it's less stressful as compare with the ordinary exam. Also they were agreed that OSCE allow chance of compensation for poor performance.

\section{RECOMMENDATIONS}

The study recommended that, OSCE should be integrated within the curriculum in conjunction with other relevant evaluation methods.

\section{REFERENCES}

[1] Bartfay, W. J., Rombough, R., Howse, E., \& LeBlanc, R. 2004. The OSCE approach in nursing education: Objective structured clinical examinations can be effective vehicles for nursing education and practice by promoting the mastery of clinical skills and decision-making in controlledand safe learning environments. The Canadian Nurse 100(3), 18-25. Benner, P. 1984. From Novice to Expert: Excellence and Power in Nursing Practice. Addison-Wesley, Menlo Park, CA, USA.

[2] Benner, P., Tanner, C. A., \&Chesla, C. A.1996. Expertise in Nursing Practice: Caring, Clinical Judgment, and Ethics. Springer Publishing, New York.

[3] Borbasi, S., \& Koop, A. 1993. The Objective Structured Clinical Examination: its application in nursing education. The Australian Journal of Advanced Nursing 11(2), 33 39.

[4] Brosnan, M., Evans, W., Brosnan, E., \& Brown, G. 2006. Implementing objective structured clinical skills evaluation (OSCE) in nurse registration programmes in a centre in Ireland: A utilisation focused evaluation. Nurse Education Today 26, 115-122. 


\section{INTERNATIONAL JOURNAL OF RESEARCH -GRANTHAALAYAH

[5] Bujack, L., McMillan, M., Dwyer, J., \& Hazelton, M. 1991a. Assessing comprehensive nursing performance: the Objective Structured Clinical Assessment (OSCA): Part 1 Development of the assessment strategy. Nurse Education Today 11, 179-184.

[6] Bujack, L., McMillan, M., Dwyer, J., \& Hazelton, M. 1991b. Assessing comprehensive nursing performance: the Objective Structured Clinical Assessment (OSCA). Part 2 Report of the evaluation project. Nurse Education Today 11, (248-255).

[7] Burnard, P. 1987. Towards an epistemological basis for experiential learning in nurse education. Journal of Advanced Nursing 12(2), 189-193.

[8] Chesser, A., Laing, M. R., Miedzybrodzka, Z. H., Brittenden, J., \&Heys, S. D. 2004. Factor analysis can be a useful standardsetting tool in a high stakes OSCE assessment. Medical Education 38, 825-831.

[9] Ellerton, M., \&Gregor, F. 2003. A study of transition: The new nurse graduate at 3 months. The Journal of Continuing Education in Nursing 34(3), 103-107.

[10] Fisher, M., \&Parolin, M. 2000. The reliability of measuring nursing clinical performance using a competency based assessment tool: A pilot study. Collegian 7(3), 21-27.

[11] Friedman Ben-David, M. (2000). The role of assessment in expanding professional horizons. Medical Teacher 22(5), 472-477.

[12] Hamdy, H. (2006). Blueprinting for the assessment of health care professionals. The Clinical Teacher 3, 175-179.

[13] Harden, R. M. 1988. What is an OSCE? Medical Teacher 10(1), 9-22.

[14] Harden, R. M., \& Gleeson, F. A. 1979. Assessment of clinical competence using an objective structured clinical examination (OSCE). Medical Education 13, 41-54.

[15] Harden, R. M., Stevenson, M., Downie, W.W., \& Wilson, G. M. 1975. Assessment of clinical competence using objective structured examination. British Medical Journal 1, 447-451.

[16] Hodges, B. 2003b. OSCE! Variations on a theme by Harden. Medical Education 37, 1134-1140.

[17] Hodges, B. 2003a. Validity and OSCE. Medical Teacher 25(3), 250-254. 16

[18] Humphrey-Murto, S., \&MacFadyen, J. 2002. Standard setting: A comparison of case-author and modified borderline-group methods in a small-scale OSCE. Academic Medicine 77(7), 729-732.

[19] Issenberg, S. B., McGaghie, W. C., Petrusa, E. R., Gordon, D. L., \&Scalese, R. J. 2005. Features and uses of high-fidelity medical simulations that lead to effective learning: a BEME systematic review. Medical Teacher 27(1), 10-28.

[20] Khattab, A. D., \& Rawlings, B. 2001. Assessing nurse practitioner students using a modified objective structured clinicalexamination(OSCE). Nurse Education Today 21, 541-550.

[21] Major, D. A. 2005. OSCEs--seven years on the bandwagon: the progress of an objective structured clinical evaluation programme. Nurse Education Today 25(6), 442454. 


\section{INTERNATIONAL JOURNAL OF RESEARCH -GRANTHAALAYAH

[22] McGrath, P., Moxham, L., Fox-Young, S., Anastasi, J., Gorman, D., \&Tollefson, J. 2006. Collaborative voices: Reflections on ongoing issues regarding nurse competencies. Contemporary Nurse 22(1), 46-58.

[23] McMullen, M., Endacott, R., Gray, M. A., Jasper, M., Miller, C. M. L., Scholes, J., et al. 2003. Portfolios and assessment of competence: a review of the literature. Journal of Advanced Nursing 41(3), 283-294.

[24] Miller, G. 1990. The assessment o clinical skills / competence / performance. Academic Medicine 65 (Suppl.9), S63-S67.

[25] Newstead, S. E. 1992. The use of examinations in the assessment of psychology students. Psychology Teaching Review 1(1), 22-33.

[26] Piercey, C. 1995. Assessing clinical competencies. In: Summers, L. (Ed), A Focus on Learning. Proceedings of the 4th Annual Teaching Learning Forum, Edith Cowan 17University, February 1995. Edith Cowan University, Perth, pp.206-211.

[27] <http://lsn.curtin.edu.au/tlf/tlf1995/piercey.html>, accessed 19.03.07.

[28] Pigott, H. 2001. Facing reality: The transition from student to graduate nurse. Australian Nursing Journal 8(7), 24-25.

[29] Rushforth, H. E. 2007. Objective structured clinical examination (OSCE): Review of the literature and implications for nursing education. Nurse Education Today 27, 481 490.

[30] Salas, E. \& Burke, C. S. 2002. Simulation for training is effective when... Quality \&Safety in Health Care 11(2), 119-120.

[31] Schuwirth, L. W. T., \& van der Vleuten, C. P.M. 2003. The use of clinical simulations in assessment. Medical Education 37 (Suppl.1), 65-71.

[32] Selby, C., Osman, L., Davis, M., \& Lee, M.1995. Set up and run an objective structured clinical exam. British Medical Journal 310, 1187-1190.

[33] Shavelson, R.J, \& Huang, L. 2003. Responding responsibly to the frenzy to assess

[34] learning in higher education. Change 35(1), 10-19.

[35] Taras, M. 2005. Assessment - summative and formative - some theoretical reflections. British Journal of Educational Studies 53(4), 466-478.

[36] Ward, H., \& Barratt, J. 2005. Assessment of nurse practitioner advancedclinical practice skills: using the objective structured clinical examination (OSCE): Helen Ward and Julian Barratt examine how OSCEs canbe developed to ensure a robustassessment of clinical competence. Primary Health Care 15(10), 37-41.

[37] Ward, H., \& Willis, A. 2006. Assessing advanced clinical practice skills: Helen Ward and Annaliese Willis show how the development of an objective structured clinical 1819assessment (OSCA) has enabled assessment of nurse practitioner advanced practice clinical skills at Masters level. Primary Health Care 16(3), 22-24.

[38] Watkins, M. J. 2000. Competency for nursing practice. Journal of Clinical Nursing 9, 338-346.

[39] Wessel, J., Williams, R., Finch, E. \&Gemus,M. 2003. Reliability and Validity of an Objective Structured Clinical Examination for Physical Therapy Students. Journal of Allied Health 32(4), 266 


\section{INTERNATIONAL JOURNAL OF RESEARCH -GRANTHAALAYAH \\ A knowledge Repository}

Science

[40] Wilkinson, T.J., Newble, D.I., Wilson, P.D., Carter, J.M \& Helms, R.M. 2000. Development of a three-centre simultaneous objective structured clinical examination. Medical Education 34, 798-807. 